\title{
University Students Teaching Environmental Science to Primary School Students as Service- Learning: Lessons Learned
}

\author{
Mark McGinley* \\ Science Unit, Core Curriculum and General Education Office, Lingnan University, 8 Castle Peak Rd, \\ Tuen Mun, Hong Kong
}

\begin{abstract}
The service-learning pedagogy attempts to enhance student learning by integrating academic study with meaningful community service. This paper discusses lessons learned when attempting to integrate direct service (having S-L students provide science lessons for primary students) and indirect service (having S-L students prepare curriculum guides for use by primary teachers) to maximize academic learning in a course entitled "Ecology: The Science of the Environment" at Lingnan University in Hong Kong. Although the course covered fewer topics when taught using the service-learning pedagogy, S-L students reported that participating in the service-learning project (i) increased their academic learning, (ii) enhanced their interest in science, and (iii) improved their communication and problem solving skills. Based on student feedback received, attempts were made to improve the service-learning experience by (i) altering the course outline so that S-L students have learned the material in class before sharing with the primary students, (ii) providing more input to the focus of their topics, (iii) allowing S-L students to interact with the primary students during their on-site orientation, and (iv) encouraging the primary school teachers to provide immediate feedback to the S-L students at the end of each lesson.
\end{abstract}

\begin{abstract}
Keywords: Direct service-learning, indirect service learning, integerate academic learning with community service, science education, STEM, university students teaching primary students.
\end{abstract}

\section{Introduction}

One goal of the Service-Learning pedagogy is to enhance student academic learning by combining it with meaningful community service and reflection [1]. Although this goal is easy to articulate, accomplishing this task can be challenging [2]. The challenge is determined, in part, by the relationship between the academic learning and service. In some courses the form of the service can be closely related to academic learning. For example, students taking a class in music education might provide service by teaching music classes at a local youth shelter or students taking an accounting class might provide service by

\footnotetext{
*Corresponding author: markmcginley@ln.edu.hk
} 
taking care of the books of a local non-profit organization. In these examples, providing service directly applies the academic skills learned in the class. In other courses there may be a larger distinction between the focus of the service and academic learning. For example, students taking a course in nutrition might provide service at a local food bank. In such a case the effort spent in service may do little to directly advance the academic learning about the topic, but instead can provide other benefits such as encouraging community engagement of service-learning (S-L) students in the future.

Here some lessons learned from the attempt to intentionally combine both direct service (e.g., developing and teaching science activities to primary students) and indirect service (e.g., developing curricular materials to support primary school teachers in using these science activities) to maximize university students' academic learning and the value of service provided in a service-learning course taught at Lingnan University in Hong Kong are discussed.

\section{The service-learning class}

The goals of the course, Ecology: the Science of Environmental Issues, offered to fulfill requirements of the Science, Technology, and Society Cluster of the Core Curriculum, are to (i) introduce students to the process of science as a way of learning about the world, (ii) introduce students to the basic concepts of ecology and important environmental issues, and (iii) enable and encourage my students to learn more and communicate effectively about complex environmental issues in the future.

Before applying the service-learning pedagogy to this class, a community need must be identified. Science, Engineering, Technology and Math (STEM) education can increase workforce readiness and competitiveness in developing countries, such as my former home, USA [3] or my current home, Hong Kong [4] as well as in developing countries such as Indonesia where there is a projected $40 \%$ annual deficit of engineers produced [5]. According to Murphy [6] "by the time students reach fourth grade, a third of boys and girls have lost an interest in science. By eighth grade, almost $50 \%$ have lost interest or deemed it irrelevant to their education or future plans." Thus, primary school can play a very important role in assuring that more students remain in the STEM pipeline. Finally, by the very nature of their job, Primary School teachers need to be the ultimate generalists, so they generally do not specialize in the sciences, or any other specific subject. Unfortunately, the expressed "self-efficacy" in science of many primary school teachers is lower than for other subject areas [7], so some primary teachers respond by limiting the time that they spend on science in their classrooms [8].

Recognizing the importance of STEM knowledge to providing a high quality workforce and educated citizenry, the Hong Kong government recently advocated increasing the focus on STEM education in the city through the development of learner-centered approaches that generate essential learning experiences including learning opportunities beyond classroom [9]. Thus, a service-learning component was added to my course by having S-L students develop and teach science/environment-related lessons and activities to primary school students. With the help of the LU Office of Service Learning projects were developed in collaboration with three partner primary schools located in Tuen Mun, Hong Kong. The logic model for this class is shown in Appendix $1[10,11]$.

i. Hing Tak School. In this project S-L students develop and lead lessons/activity for a mixed group of primary students in an afterschool enrichment program. During the initial term these lessons broadly focused on a range of topics in environmental science but in the current term the lessons focused on introducing students to "aquaponics".

ii. H.K.E.C.A. Wu Si Chong Memorial School. In this project S-L students used of the school's audio-visual facilities to help the primary students develop short "TV shows" 
about science to share with other students in the school. In this project, the S-Ls students must educate the primary students about the topic of the TV show as well as direct the production and final editing of the videos. In the first term the shows focused on "animal diversity" and "mammals" and in the second term the shows focused on "aquaponics" and "plants".

iii. RTG Gaia School. During the first term of this project two groups of S-L students developed and conducted lessons/activities covering a range of topics related to science and the environment to two different groups of primary students. During the second term, two groups of S-L students worked with the Gaia School; one group worked with Primary three students on lessons/activities focused on "solid waste" and the second group is worked with secondary school students on a Saturday enrichment project focused on "stream ecology and geomorphology".

\section{Concerns}

There were three main concerns while designing this course. (i) The level of content appropriate for primary students is so far below the level appropriate for university students that working with primary students might not enhance academic learning of university students. (ii) The service-learning project (planning, reflection, etc.) would take away significant class time and student effort that could be spent on content learning. (iii) How can the amount of service provided by the S-L students be maximized to assure the efforts have the greatest outcomes and impacts? (see logic model, Appendix 1).

\section{The solution}

At first look, the great disparity between the level of content knowledge appropriate at the university and primary school levels might minimize the effectiveness of this type of service for university student academic learning. However, the Nobel Prize winning Physicist Richard Feynman suggested that the best way to learn new complex material (the Feynman Technique) is to (i) attempt to teach it to a child, (ii) review the knowledge gaps, (iii) organize and simplify the information, and (iv) try explaining the material to an adult [12]. Thus, incorporating the Feynman Technique by intentionally combining both direct service (e.g., developing and teaching science activities to primary students) and indirect service (e.g., developing curricular materials to support primary school teachers in using these science activities) might be an effective strategy for maximizing university students' academic learning.

This strategy was used in Term $12016-17$ (Fall Term) and, after some modifications, in Term 2 2016-17 (Spring Term). S-L students formed groups to develop and provide educational activities to primary students. As part of their final project for the course students were required to (i) choose one lesson/activity or related set of lessons/activities, (ii) provide instructions in sufficient detail to allow a novel teacher/educator to conduct the activity/lesson, and (iii) write a "curriculum guide" that would provide the information required to provide teachers with sufficient background knowledge and confidence that they are able to independently and confidently conduct the lessons/activities. The curriculum guides should (i) clearly state the intended learning outcomes of the activity and relate these to the learning outcomes listed in the HK General Studies program, (ii) summarize the critical background information related to the topic, and (iii) provide links to websites/videos that would help teachers to master the background content material. Thus, writing the curriculum guide was similar to writing a term paper that is intended to be read by a non-expert. 


\section{Effectiveness of the service-learning experience}

We evaluated Lingnan student's S-L experience by a number of methods including preand post-course questionnaires, student focus groups organized by the Office of Service Learning, comments during in-class reflections, and post-project written reflections. In addition, a post-course debriefing was held along with staff from the Office of Service Learning and post-course debriefing sessions were held with staff from each of the schools. After the completion of the first S-L collaboration between partner schools, the Office of Service Learning, it was concluded to continue the collaboration for a second term which is still ongoing. Thus, all data and student comments presented here were collected after the first term.

Overall the S-L students reported a high level of satisfaction with the S-L learning course and with their service practicum in particular (Table 1).

Table 1. Mean level of satisfaction of S-L students with the S-L course overall (overall satisfaction) and their service project (service practicum) $1=$ least satisfied, $10=$ very satisfied.

\begin{tabular}{|l|c|c|c|c|}
\hline & AM Gaia & PM Gaia & Hing Tak & Wu Si Cheong \\
\hline $\begin{array}{l}\text { Overall } \\
\text { Satisfaction }\end{array}$ & 7.71 & 7.20 & 7.92 & 7.75 \\
\hline $\begin{array}{l}\text { Service } \\
\text { Practicum }\end{array}$ & 8.57 & 7.30 & 8.31 & 7.50 \\
\hline
\end{tabular}

\subsection{Working with primary students}

Many S-L students noted positive experiences while working with primary students in their open-ended responses on the post-course questionnaires and in their final written reflections.

"We helped the community gain interest in science."

"The project could pass science knowledge and care to the school kids in Gaia School."

"Transfer the importance of reducing pollution to the primary students"

"Throughout the whole project, I have found it satisfying to interact with younger children and transmit some scientific or environmental messages and knowledge to them and I have learnt an important skill on how to present ideas in ways that suit the needs of the audience, which is useful in many aspects in daily life. Particularly, this course and this service-learning experience have raised my awareness and incentive to participate on how to improve Hong Kong's education system, so students could get in touch with the nature in real but not just reading it on textbook and reciting scientific theories for exam."

"Our aim is to make the students enjoy learning sciences. We are not professionals; we may not provide so much advanced knowledge in sciences. What we can do is to use our limited resources and knowledge to encourage primary students to learn and think. I think we have done a great job in achieving our aim as the students in class really being encouraged to ask and learn about science. Most of them were having a smiling face during the class. Teaching was not only simply transferring knowledge, but also teaching the attitude of learning. The act of the student reminds me I should ask more and think deeper in the lesson in university. From the service learning project to Hing Tak in this term, I learn a lot more than I expected." 


\subsection{The Gaia School experience}

As indicated by the following statements from the RTG Gaia School website, the Gaia School offers a unique educational experience in Hong Kong [13]. "We value learning experience over learning outcomes. Teachers would try their best to ensure a fun and challenging learning process for the children. With multiple class activities and games, children learn in an environment which encourages them to raise question and to look for answers, which develop their capabilities to solve problem and to learn by themselves." "Education at the Gaia School is guided by the following values: (i) Teaching and learning happen spontaneously, regardless of time and space. Every interaction could be a point in learning and an embodiment of the integration of living and learning. (ii) Teach by examples. Teachers influence the children by how they act and live. (iii) Nature and social environment are important to teaching and learning. (iv) Teaching children according to their unique talents and abilities. (v) Teachers give positive feedback to children."

In particular, the teaching style at the Gaia School is quite different from that used in traditional schools in Hong Kong. "When students are used to learning under the pressure of parents and teachers instead of out of his/ her own wish, they do not understand why they should learn and many would think that schools are boring. In Gaia School, we decide to abandon the authority as we believe that children are born curious and they have the natural desire to learn. With a natural environment, children should be able to find things that interest them." Thus, the Gaia School offers a lot more freedom to its students who are free from having to participate in any activities!

Thee uniqueness of the Gaia School approach was experienced during my first class observation at the school. It was surprising that most of the students appeared to be paying little attention to the teacher as she explained the upcoming activities planned in the garden. Instead, many students were moving around the classroom, looking at unrelated books, talking among themselves, or simply staring into space. It was even more surpriseing when the teacher did not appear to be at all concerned about such behavior! However, it was impressive and amazing that when the teacher finished giving instructions all of the students enthusiastically moved to the garden, became engaged their chosen activity, and worked with great attention and interest requiring very little guidance from the teacher! It was intriguing to consider how Lingnan University S-L students would react to educational style that differed greatly from their own school experience.

Not surprisingly, initially many S-L students found teaching this less-structured environment to be challenging and frustrating, but over time they came to appreciate aspects of the educational approach and the unique personalities and abilities of the Gaia students.

"From being extremely frustrated to genuinely enjoying the time spent with the kids, it has been quite a long yet unforgettable journey."

The key moment of transition occurred when S-L students began to interact, either one on one or in small groups, with Gaia students working on projects during their lessons. The Gaia students, who were not shy about showing their disinterest in "boring" activities, participated with great enthusiasm when interested, engaged, and challenged. With experience the S-L students became better at creating these teachable moments. Many students noted positive experiences working with students from the Gaia School in their open-ended responses on the post-course questionnaires and in their final written reflections

"By teaching students in Gaia School, I understand the needs of children- learning through playing."

"I have a deeper understanding on how current education system negatively affects the children." 
"The students in Gaia School are energetic, they have creative thoughts that we lack... In this $\mathrm{S}-\mathrm{L}$ project I have a better understanding that there are some non-traditional schools which educate the students in a very different way."

"There is no doubt to say that students in Gaia School have less discipline. However, from my observation, less discipline is good for their learning, in particular, creativity development. One student in our class has already proved this point. When the students were doing the leaf burning experience, one students found that he could not do it well as he could not hold the magnifying glass stably so he ran back to the classroom and took out some tools that can help him such as books, rulers and even his school bag. Although his action was totally unacceptable for teachers teaching in traditional primary school, I was impressed by his creativity and innovative mind."

"This practicum is probably a once-in-a-lifetime experience. At first, as joining servicelearning program is the prerequisite for Lingnan students' graduation so I just wanted to finish it as soon as possible. However, once I got to know more about the school, the teachers and the students in Gaia school. My views towards service learning program have completely changed. In my opinion, teaching in Gaia School is not only about educating the students over there, it is also a chance for me to learn from this experience. For example, before we visit the school, we had to prepare the materials for the class. Also, we had to try the experiment for a few time to ensure even a primary student can achieve the result successfully. The process took my partner and I quite a lot time, but we found it worth doing as we can learn through the preparation. I realized that I have learned many things from this experience, not only the knowledge from textbook, but also the sense of dealing with the students and working with other group members into harmony in unity, or coping with different kind of things with proper attitude while we discover the problem. I will never forget this experience, and I will definitely grab more chances to work on service learning projects as I wish to do more meaningful things in the future."

\subsection{Relationship between service and academic learning}

The major concerns faced while teaching this course were (i) that time spent on servicelearning activities (introduction, planning, reflection, etc.) would take away from class time or student effort that could be spent on academic learning and (ii) whether the level of knowledge required to offer science lessons to primary students would be too low to encourage academic learning at the non-majors university level.

Clearly, the class time allocated to service-learning reduced the number of topics and issues covered in class. One "quantitative measure" of the amount of information covered in the class is the number of lessons, major in-class activities, and PowerPoint presentations posted the online course management system (Moodle). Only $82 \%$ as many lessons were posted on the Moodle as when the course was taught in the traditional manner indicating that students in the SL course were exposed to fewer topics/issues, and occasionally to less detail, than students in the traditional course. Hopefully, this course to provide my students with the broadest possible exposure to environmental issues. It is hoped that in the future, when they are exposed to information about an environmental issue, they will think "I remember when we talked about that in the Ecology class" and they will be able to use the knowledge and skills from this class to become more informed about the issue on their own. Thus, it is concerning if the S-L students are exposed to fewer issues using the service-learning pedagogy. In response, the trade-off between the number of topics and the depth of coverage in future classes will be reevaluated to determine how to make the best use of the reduced time devoted to academic learning.

Unfortunately, no "experimental tests" to investigate the effect of the service-learning pedagogy on student learning were conducted, so all conclusions are based soley on 
students' evaluations of their own level of academic learning. Students indicated a strong increase in their self-assessment of their "subject-related knowledge" between the pre- and post-course questionnaire (pre-course-6.61, post-course-7.59). During in-class reflections near the end of the S-L course, students were explicitly asked whether they thought that the level of academic learning they achieved during their S-L activities was large enough to offset the smaller amount and depth of academic material covered in class. Almost uniformly, students said that they thought that the trade-off was worth it. In fact, the only exception was a student with an especially strong science background who was hoping to be exposed to more challenging material.

During in-class reflections many S-L students discussed how preparing for their lessons increased their science knowledge. Equally importantly, they discussed how they were forced to search for reliable information on the internet, sift through the available material, and then organize the information before presenting it to the students. From my perspective as an instructor of a general education course to non-science majors, locating and processing scientific information is one of the most valuable skills for students develop.

On the post-course questionnaire and their final written reflections S-L students discussed how their participation in the S-L project positively affected their academic learning during the course.

"I did more research on the science topic I learnt before giving lessons to primary students."

"We need to have a better understanding on the course materials before educating the students."

"Application of learning- use what I learned in the lecture, and then make it simpler and transfer to the primary school students."

"Through holding the lesson, I taught base on a broader and deeper understanding of the course materials."

"Because what our group decided to teach was linked back to the content of our course, as a result, we could have a deepened understanding when we did the research and teaching."

"The last time I have learnt about classification of animals would be back to the time of high school." After knowing the main topic of the third practicum, to be honest, I have forgotten most of the things about it. So, in order to prepare for the lesson, I found my secondary school textbooks and revised, and that I recalled my memory. However, as a "teacher" during the practicum, I did not think what the textbook says would be enough. Therefore, I did look for more information on the Internet. Actually, it was also the first time for me to look at so many animals' photos and information for such a long time. As I found more and more information, it was surprising to me that I would have a feeling that I would like to tell all the things I have found out to the primary school students like a sharing between friends, for instance, the evolution of animals, why we can find mammals in different places and why mammals have so many different characteristics."

"There is no doubt that this practicum has increased my science knowledge." Originally, I think that it is easy for me to teach basic knowledge about the environment pollution. In fact, when preparing the class material for the practicum, I found out that I am also not very clear and sure about the details of the environmental problems. By finding materials online, I could at the same time enriching my science knowledge."

\subsection{Influence of writing the curriculum guide}

The curriculum guide students prepared as part of their S-L project replaced the final term paper that were assigned in my traditional courses. The hypothesis was that writing a curriculum guide would provide a more valuable learning experience for two reasons. 
First, preparing the curriculum guide will be the final step of the Feynman Technique. Second, it is proposed that students might work harder and with greater care when writing materials that might potentially be used in the future than when writing a term paper that they know will be graded by the professor and then ignored. A small research project is planned to explore whether student efforts or attitudes towards their writing assignments are altered when producing a "more meaningful" assignment.

One student referenced the curriculum guide in their responses on the post-course questionnaires.

"Our curriculum may be published so it may let more schools know how to teach science knowledge to students."

\subsection{Service-learning student interest in science}

Increasing student interest in the topic is an explicit goal in all general education courses. Because under the current system, most students at Lingnan University will take only one science course during their university career, there are limited opportunities to excite students about the field of science. Student comments on the post-course questionnaire and final written reflections indicated that their service learning experience increased their level of science interest.

"Generally, I'm more interested in Science now and its impact on our world. Due to that, I enjoyed learning in the class time and paid more attention to the lessons as well."

"The project provided us with an opportunity to apply what we learned in the course to the service practicum, hence into genuine experiences."

"Being the role of teacher of the primary students, I also gained a lot from this service learning project. First, it helped me to revise my knowledge on science. I actually have learned some of the topics such as food chain and classification of living organism when I studied in primary school and secondary school. However, I have forgotten about the details. No matter being an audience or the person who teach can also help me to revise about the topics and even learn something new. In addition, this service learning project has aroused my interest in science. When I was a secondary student, I thought that science was very boring and difficult. Yet, after this experience, I found that there is much more interesting knowledge in science and I am willing to take science course in the future."

\subsection{Communication, organization, research, and problem-solving skills}

The results of pre- and post-course questionnaires indicated that student self-assessment of their communication skills (pre-course-6.84, post-course-7.77), organizational skills (pre-course-6.71, post-course-7.59), problem-solving skills (pre-course-6.96, postcourse-7.76), and research skills (pre-course-6.58, post-course-7.44) increased over the term. In addition, when asked during the two post-course focus groups conducted by staff from the Office of Service Learning to identify their greatest gain from involvement in S-L project, members of one focus groups stated (i) communication skills and (ii) initiative to search for resources and members of a second focus group stated (i) reflection on Hong Kong education system and (ii) improvement in communication skills, problem solving skills, and classroom management skills. One student expressed similar thoughts during their written reflection.

"After this services learning experience, I feel like fall in love with services learning. I enjoy the feeling that I can make good change to others and myself. Compare to lecture, services learning are more real, I can combine my knowledge to help the society. I learn skill that can't learn from only listening to what teacher speak such as organising and 
cooperating with different background people and contingencies. I am going to join more services learning in different aspects to enlarge my knowledge base."

Because these gains line up nicely with the skills outlined as the Attributes of a Lingnan Graduate (excellent interpersonal communication ability, strong analytic competence and a capacity for independent critical thinking, and creative and sound problem-solving and planning capabilities), it appears that this S-L experience helped participants to develop skills valued by the University. Thus, the addition of a servicelearning graduation requirement at Lingnan University might be an important tool for developing desired graduate attributes.

\section{Results}

Not surprisingly, this attempt at leading a service-learning course was far from perfect, so there remains plenty of room for improvement. Fortunately, students had many opportunities to provide feedback so they were able to provide variety of suggestions of how to improve the service-learning component of the course. First, better coordination between the order that topics were covered in the class and the topics that they were teaching to the primary students would allow them to be more familiar with the topic before entering the classroom. Second, students' orientation to the primary school could be improved by allowing them to meet and interact with the primary students prior to their initial teaching session. Third, receiving more guidance about what topics they should cover would be prefered by the students. Fourth, the students valued feedback from the primary teachers immediately after each lesson was completed. Finally, more interaction with the primary students by increasing both the length and number of visits to the primary schools was requested.

In response, the course outline was altered so that more of the information they were teaching was addressed earlier in the term. In collaboration with the schools the agency orientation sessions were altered. Teachers organized "ice-breaking" activities to allow the S-L and primary student to interact prior to their first lesson. In collaboration with the supervising primary teachers, the scope and goals of each group were clearly outlined to provide the S-L students with a more coherent frame-work for their lessons.

Reordering the sequence of topics in the course helped provide students with more information prior to developing their lessons/activities for the primary students but it did come at some cost. Ecology is a hierarchical topic, i.e., individuals can be arranged in populations which are parts of a community, which are part of an ecosystem, which are, in turn, part of the biosphere. Traditionally, the course was taught from the lowest level to the highest attempting to show how knowledge of the level below and above informs what is happening at that level. In the new order, the course started with topics from the middle of the hierarchy. It is possible that "bouncing" back and forth between may not provide such a well-integrated introduction to the topic.

Alternatively, rather than disrupting the order of topics, it might be possible to develop online-learning support materials to provide some of the basic information that they need to conduct their S-L projects. Such a strategy might provide sufficient background information to begin their projects yet allow them to gain increased understanding of the context of the topic when the topic is covered in more detail in the appropriate course sequence.

Initially, S-L students only met with teachers and administrators during their initial orientation visit to the schools. In the second term, interactions with the primary students were included as part of the orientation which was effective for two reasons. First, the S-L students were able to observe a model of good interactions with the students through the ice-breaking games organized by the primary teachers and second, the S-L students were 
more familiar with the primary students and were more comfortable during their initial lessons.

During post-course discussions with the primary teachers, it was agreed that the broad scope of each project and the specific topics of each session should be more clearly defined. Increasing the focus of projects during the second term improved quality of the service the S-L students have provided because the S-L students were emphasize the links between the different lessons which increased the overall learning of both S-L and primary students.

After learning how much the S-L students appreciated immediate feedback from the primary teachers, all teachers were asked to end each session by critiquing how they thought the lesson went, what the S-L students did well during the lesson, and how their efforts might be improved in the future? These feedback sessions will become a regular part of school visits during the current term.

It is true that there is a limit to how much learning can be accomplished in a $1 \mathrm{~h}$ time slot and in a limited number of teaching sessions in the term, but unfortunately, working with the schedule provided by the cooperating primary schools made it impossible to increase the frequency or duration of class visits for most projects. During the second term one S-L group worked with secondary students from the Gaia School for $6 \mathrm{~h}$ on four successive Saturdays during April. Extending the time for interaction with the students, the more advanced abilities of secondary students, and the proximity of natural areas, including a stream, to the school allows the S-L students to provide more engaging and challenging experiences to these students.

The loss of class time to service-learning related activities eliminated the time spent in the traditional class for students to learn how to design and conduct independent research projects using air pollution data from Hong Kong Observatory. Because being able to "demonstrate an understanding of scientific methods, hypothesis development, and issues of measurement and data collection" was a key intended learning outcome of courses in the Science, Technology, and Society Cluster, students who took the service-learning course did not receive as strong of an introduction to that topic. Fortunately, Lingnan University has decided to add a new required science course to the Core Curriculum that will be taken by all students. Because the new course will focus on the process of science, students who take S-L courses will still be able to meet that important learning outcome.

\section{Discussion}

It is difficult to quantitatively determine differences in the amount or quality of academic learning by students in S-L compared to traditional classes. It is proposed that student learning through service-learning was "different" than from that in a traditional class. The S-L students showed a high degree of enthusiasm when working with the primary students so hopefully their memories of these experiences and some of the related science information will stick with them over time. More importantly, throughout their service project the S-L students used many of the skills that it was hoped they would develop such as locating reliable information, organize information about complex topics, and communicating effectively with a non-expert audience.

The Feynman Technique of first teaching the material to a child, rethinking, and then attempting to teach it to a general audience can be a good model for how to combine direct and indirect service in an attempt to maximize S-L student academic learning and the service provided. Elsewhere, McGinley (in prep) has suggested that mathematical models, a tool that has effectively guided the development of theory and practice in many fields of science, engineering, and economics can be a useful tool to educators, including those interested in service learning. The results of these models predict that the "value" of a service learning class can be maximized when the instructor can (i) reduce the tradeoff 
between time and effort allocated to academic learning and service and (ii) create positive synergisms between service and learning (i.e., S-L students learn more from being involved in a service project). Applying the Feynman Technique in S-L courses might effectively meet both of these needs and thus be a good teaching and learning strategy.

In summary, having university students develop and teach science lessons to primary students provided a value community service opportunity. S-L students reported that participating in the service-learning project (i) increased their academic learning, (ii) enhanced their interest in science, and (iii) improved their communication and problem solving skills.

The author would like to thank the administrators, teachers, and students at three partner schools and the administration of the LU Office of Service Learning, Professor Robin Snell, Dr. Carol Ma, and Dr. Albert Ko, for their cooperation and support. Thanks to Lam Lai Ki (Joy) and Chan Wing Yee (Constance) for helping to establish collaborations. Thanks also to Joy for serving as the S-L Coordinator for my classand to the three wonderful undergraduate OSL Teaching Assistants, Serena Wong, Chan LaiMing (Amin) and Tony Tse, who helped to improve the experience greatly. Finally, the patience, enthusiasm, creativity, caring, and effort of the Lingnan students in CLD9017 Terms 1 and 2 is appreciated.

\section{References}

1. A. Furco, Service-learning: a balanced approach to experiential education, expanding boundaries: serving and learning. Washington DC: Corporation for National Service (1996).

http://www.shsu.edu/academics/cce/documents/Service_Learning_Balanced_Approach To Experimental Education.pdf

2. J. Eyler, D.E. Giles jr. Where's the learning in service-learning?. San Francisco: Jossey-Bass (1999). https://www.amazon.com/Wheres-Learning-Service-LearningJanet-Eyler/dp/0470907460

3. National Science Board. Revisiting the STEM workforce: A companion to science and engineering indicators. USA: National Science Foundation (2014). https:/www.nsf.gov/pubs/2015/nsb201510/nsb201510.pdf

4. The Academy of Sciences of Hong Kong. Science, technology and mathematics education in the development of the innovation and technology ecosystem of Hong Kong. Hong Kong: The Academy of Sciences of Hong Kong (2017). http://www.ashk.org.hk/extensions/fileman/Uploads/FULL_report_Eng_28_12.16\%20v $\underline{1 . p d f}$

5. J. Cochrane, Indonesia's dire need for engineers is going unmet. The New York Times, [Online] from https://www.nytimes.com/2016/12/18/world/asia/indonesias-dire-needfor-engineers-is-going-unmet.html (2016). [Accessed on September 26, 2018].

6. T. Murphy, STEM education- it's elementary. Elementary school teachers need to be educated in science and math. US News and World Report, [Online] from https://www.usnews.com/news/articles/2011/08/29/stem-education--its-elementary (2011). [Accessed on September 26, 2018].

7. R.R. Buss. Sch Sci Math 110,6:290-297(2010). https://onlinelibrary.wiley.com/doi/abs/10.1111/j.1949-8594.2010.00037.x

8. J.E. Petersen, D.F. Treagust. AJTE 39,9:153-167(2014). https://files.eric.ed.gov/fulltext/EJ1038100.pdf 
9. Curriculum Development Council. Promoting STEM education: unleashing potential in innovation. Hong Kong: Curriculum Development Council (2016) https://www.edb.gov.hk/attachment/en/curriculumdevelopment/renewal/Brief\%20on\%20STEM\%20(Overview) eng_20151105.pdf

10. W.K. Kellog Foundation, Logic model development guide. Using logic models to bring together planning, evaluation, and action. Battle Creek, Michigan: W.K. Kellog Foundation (2004). https://www.bttop.org/sites/default/files/public/W.K.\%20Kellogg\%20LogicModel.pdf

11. E. Taylor-Powell, E. Henert. Developing a logic model: Teaching and training guide, University of Wisconsin-Extention. Madison, Wisconsin: Cooperative Extension (2008)

https://peerta.acf.hhs.gov/sites/default/files/public/uploaded_files/Logic $\% 20$ Model $\% 20$ Guide.pdf

12. B. Crew. 3 simple steps to mastering any new subject, According to a Nobel Prize winning physicist, Science Alert, [Online] from https://www.sciencealert.com/3-simplesteps-to-mastering-any-new-subject-Nobel-Prize-winner-Richard-Feynman (2018). [Accessed on September 26, 2018].

13. Gaia School. Primary section. [Online] from http://www.gaiaschool.edu.hk/en/curriculum/primary-section/ (n.d.). [Accessed on September 26, 2018]. 
Appendix 1. Logic models for the two Service-Learning projects, "developing science lessons" and "producing TV shows" (S-L =

Service-Learning students, LU = Lingnan University, PS = Primary School; OSL = Lingnan University Office of Service Learning)

\section{"Developing Science Lessons"}

\section{Resources}

1) S-L students

2) LU Professors

3) LU OSL support

4) PS cooperation

\section{Activities}
1) S-L students develop lessons and experiential lessons for PS students
2) Develop curricular materials to support teachers

\section{Outputs}

1) S-L students lead activities \& lessons for PS students

2) PS teachers receive curricular materials for future use

\section{Outcomes}

1) PS students increase their scientific knowledge

2) PS students increase their science experience

3) PS students increase their inquiry skills

4) PS students gain experience with environmental issues

5) PS students have fun while learning about science

6) S-L students gain teaching and communication experience

7) S-L Students increase their science content knowledge

\section{Impacts}

1) Increased student scientific achievement (S-L and PS)

2) Increased student interest in science (S-L and PS)

3) Increased interest in pursuing a scientific career

4) More scientifically literate citizens with

5) More environmentally literate citizens

6) Increase interest in S-L students in pursuing a career in teaching

\section{"Producing TV Shows"}

\section{Resources}

1) S-L students

2) LU Professors

3) LU OSL support

4) PS cooperation

5) Campus TV support

\section{Activities}
1) S-L students develop lessons and experiential lessons for PS students; help PS develop TV show
2) Develop curricular materials to support teachers

\section{Outputs}

1) S-L students lead activities \& lessons for PS students and help create TV show

2) PS teachers receive curricular materials for future use

\section{Outcomes}

1) PS students increase their scientific knowledge

2) PS students increase their science experience

3) PS students increase their inquiry skills

\section{Impacts}

1) Increased student scientific achievement (S-L and PS)

2) Increased student interest in science (S-L and PS)

3) Increased interest in pursuing a scientific career 
4) PS students gain experience 4) More scientifically literate citizens with environmental issues 5) More environmentally literate citizens

5) PS students have fun while learning about science

6) Increase interest in S-L students in 6) S-L students gain teaching pursuing a career in teaching and communication experience

7) S-L and PS students increase their science content knowledge 